for foundry work ; that the ill-effects of one constituent can at best be only imperfectly neutralised by the addition of another constituent ; that there is a suitable proportion for each constituent present in cast-iron, depending upon the character of the product desired, and upon the proportion of other elements present; and that variations in the proportion of silicon afford a reliable and inexpensive means of producing a cast-iron of any required mechanical character which is possible with the material employed.

Krupp's hot-blast pyrometer, which wa; shortly described, consists of an arrangement by which the hot blast is drawn with a fixed proportion of cold air into a chamber, the temperature of which, being measured with an ordinary thermometer, gives that of the hot blast by calculation.

ON DISSOCIATION TEMPERATURES, WITH SPECIAL REFERENCE TO PYROTECHNICAL QUESTIONS ${ }^{1}$

IN bringing the subject of dissociation before the Royal Institution of Great Britain, the author proposed to confine himself to its influence on combustion and heating, that is to say, to its effects on combustible gases and the products of combustion, and on furnace work generally. His researches had been made for the most part in connection with large gas furnaces constructed according to his new system of working with radiated heat, or what may be otherwise called free development of flame. In the first or active stage of combustion the flame passed through a large combustion chamber (all contact with its surfaces being avoided), and parted with its heat by radiation only; while in its second stage the products of combustion were brought into direct contact with the surfaces and materials to be heated, by which means the remainder of its heat was abstracted. This, in a few words, was a description of the method of heating with free development of flame. In perfecting this system of furnace, the principle of which was in many respects the reverse of that generally accepted, both as regards construction and working, he had to examine into the accuracy of certain scientific theories which could not be brought into harmony with the actual results he obtained.

Adopting the generally-accepted theory of combustion, according to which a flame consists of a chemically-excited mixture of gases, whose particles are in violent motion, either oscillating to and from each other, or rotating around one another, it followed that any solid substance biought into contact with gases, thus agitated, must necessarily have an impeding effect on their motion. Motion being the primary condition of combustion, the latter would be more or less interfered with, according to the greater or less extent of the surfaces which impede the action of the particles forming the flame; in the immediate neighbourhood of such surfaces the combustion of the gases would cease altogether, because the attractive influence of the surfaces would entirely prevent their motion; farther off, their combustion would be partial, and only at a comparatively great distance the particles of gas would be free to continue unimpeded the motion required to maintain combustion. On the other hand, the surfaces themselves must suffer from the motion of the particles of gas producing the flame, for, however small these particles might be, they produce, while in such violent motion, an amount of energy which acting constantly would in time destroy the surfaces opposed to them, just as "continual dropping wears away stone." This circumstance fully accounted for the fact that the inner sides of furnaces, and the materials they contained were soon destroyed, not by heat, but by the mechanical, and perhaps also by the chemical, action of the flame. It would seem strange that the heating power of a large volume of flame should be so much interfered with by the contact of its outer parts only with the inner sides of a large furnace chamber, if there was not another cause besides imperfect combustion to reduce the heating effect of a flame which touched the surfaces to be heated. A flame when in a state of combustion radiated heat not only from its outer surface, but also from its interior by allowing the heat to radiate through its mass. In this manner every particle of flame sent its rays in all directions, but if the flame itself touched anywhere combustion ceased there, free carbon was liberated and produced smoke which enveloped that part and prevented the rays of heat of the other portions of the flame from reaching it. ${ }^{\mathrm{I}}$ Lecture by Mr. Frederick Siemens at the Royal Institution, Friday,
May 7 .
The author had avoided for various reasons referring to the subject of dissociation until recently, although it had been brought forward by several writers, and used as an argument against his new system of furnace ; as according to these writer it would appear to be impossible to produce such exceedingly high temperatures as he claimed to reach. $\mathrm{He}$ had long held the opinion that appearances of dissociation not being observable in furnaces heated by radiation, but occurring in furnaces in which the flame was allowed to come into contact with surfaces, must be due to the action on the flame of those surfaces at high temperature. He was led to this conclusion partly from his own observations, and partly from descriptions of dissociation observed by others, amongst whom was his brother the late Sir William Siemens, who described a case of dissociation (see lecture delivered March 3, 1879, at the Royal United Service Institution, entitled "On the Production of Steel, and its Application to Military Purposes") which occurred in a regenerative gas furnace constructed according to their old views of combustion and heating. The conclusion at which he hat arrived was, that solid surfaces, brsides obsiructing active combustion, must also at high temperaturts have a dissociating influence on the products of combustion.

In order to obtain information on this subject he examined the laws and theory of dissociation, and endeavoured to bring the various results obtained by scientific authorities into agreement with one another, and with his own experience, but failed entirely in doing so. The temperatures of dissociation of carbonic acid and steam, the two principal gases forming the products of combustion when ordinary fuel was used, vary very much according to these ofservers, and the results he had obtained in practice were different from most of them. He hoped to prove that the temperature at which dissociation sets in is, in most cases, much higher than generally admitted; and that the authorities he was about to refer to had omitted in almost all the experiments they had made to take into proper consideration one element which was liable to alter materially the results obtained by them. This element was the apparatus used for those exp.riments as regards its surface, form, and material.

In considering the question of dissociation, he proposed to commence with Deville, who first discovered and called attention to the dissociation of gases at high temperatures. He made numerous experiments with various gases, and fixed certain temperatures at which he found that either complete or partial dissociation took place. Without going into details, he might mention that Deville required to use vessels and tubes of definite dimensions, material, and structure, in order to obtain the results stated. One experiment had to be made with a porous tube, another required the use of a vessel with rough interior surfaces, or containing some rough or smooth material. In this way Deville arrived at a great variety of results, and although he did not state that the rough surfaces, or porous tubes, or the solid material placed inside the vessels which he employed, had any particular influence on the temperature at which dissociation took place, yet it would appear that he could not obtain his results without having recourse to those means. Deville's results depended very much upon the various kinds of surfaces he used in his experiments, if they were not entirely brought about by them; these experiments, moreover, were of a very complicated nature, so he proposed to pass on to more modern authorities, whose experiments were of simpler character, and less open to objection.

The most important experiments which modified those of Deville were due to Bunsen. Bunsen observed the dissociation of steam and carbonic acid by employing small tubes filled with an explosive mixture of these gases, to which suitable pressuregauges were attached. On igniting the gaseous mixture, explosion took place, and a high momentary pressure was produced within the tube ; from the pressure developed, Bunsen calculated tho temperature at which the explosion took place, and found that it varied with the mixtures employed. He records the circumstance that only about one-third of the combustible gases took part in the explosion, from which circumstance he concluded that the temperature attained was the limit at which combustion occurred. To prove this, Bunsen allowed the gases sufficient time to cool, after which a second explosion was produced, and even a third explosion when time was allowed for the gases to cool down again. Bunstn obtained much higher temperatures $f, r$ his limits of dissociation than other physicists these were for steam about $2400^{\circ} \mathrm{C}$., and for carbonic acid about $3000^{\circ} \mathrm{C}$. These temperatures were probably higher than 
are reached in the arts, as materials used in furnace-building would not withstand such temperatures for any length of time ; but still he must call attention to the circumstance that if the influence of the inner surfaces of the tubes on the combustion of the gases therein could be removed, the dissociation temperatures arrived at would be found still higher. He could not admit that Bunsen's explanation of the cause of the second and third explosions was quite satisfactory, as it was not the cooling of the gases alone which rendered the subsequent explosions possible, but also the thorough re-mixture of the gases by diffusion after each explosion. This he illu trated by means of diagrams which represented-

(I) A tube filled with an explosive gas mixture which was shown white.

(2) The same tube immediately after an explosion had taken place, with a white margin to indicate the unexploded mixture close to the sides, and deep red, towards the middle of the tube, the exploded gases. The white was shuwn as merging into deep red by degrees, because close up to the sides the surfaces prevented explosion or combustion altogether; nearer the middle partial combustion took place, whilst only in the middle of the tube the gases found sufficient space for complete combination.

(3) The same tube after the burnt and unburnt gases had mixed by means of diffusion, which was coloured light red.

(4) The same tube immediately after the second explosion, coloured light red at the sides, turning into deep red by degrees towards the middle.

(5) The same tube after diffusion bas done its work a second time, coloured a deeper shade of red.

(6) The same tube after the third explosion, colsured nearly deep red throughout, but still a lighter shade on the sides.

In Bun en's inode of determining dissociation at high temperatures we had only to deal with the obstruction which surfaces offer to combustion, leaving out their dissociating influence at high temperatures, which affected most of Deville's results. For that reason Bun -en arrived at much higher dissociation temperatures than Deville, and his mode of experimentin, possessed the advantage that it might lead to a proper settlement of the question of temperatures at which dissociation would set in when taking place in a space unencumbered by surfaces.

By taking a narrow tube of about the same size as Bunsen used for his experiments, and a hollow sphere of the same capacity, in both of which Bunsen's experiment should be repeated, the real dissociation temperature, if no surfaces were present to influence the result, might be approximately calculated.

Bunsen's method of experimenting, according to his view of the matter, should form the foundation of further research to determine the dissociation temperatures of products of combustion. Even if means were found for eliminating the influence of surfaces, no known material at our disposal could withstand the very high temperature to which the vessels or tubes would be subjected if experiments were carried out according to Deville's method.

That the surfaces of highly heated vessels or tubes either produce, or tend to produce, dissociation, had been corroborated lately by two Russian experimentalists, Menschuțin and Kronowalow. These gentlemen found that dissociation of carbonic acid and other gases was much facilitated when the vessels used for the experiments were filled with material offering rough surfaces, such as asbestos or broken glass.

'The lecturer's view of the theory of dissociation caused or influenced by surfaces might be given as follows. Increase of temperature producing expansion of gases would reduce the attractive tendency of the atoms towards one another, or, in other words, diminish their chemical affinity. In the same ratio as the temperature was increased the repelling tendency of the atoms must increase also, until at last decomposition, or what is called dissociation, took place. This being admitted, it would follow that the adhesive or condensing influence of surfaces on the atoms of the gas, which action would increase at high temperatures, would assist this decomposition by increasing the repelling tendency of the atoms.

Victor Meyer, who at first disputed the accuracy of the results obtained by the two Russian physicists, ultimately accepted them, thus confirming the results he had arrived at in practical work with furnaces. Thus the question might be considered nearly settled, the more so as Meyer was himself a great au- thority in questions of dissociation, having carried out many interesting experiments. Meyer, for instance, proved dissociation by dropping melted platinum into water, and found that oxygen and hydrogen were evolved from the steam produced. There could be no doubt on this point, but the question arose whether heat was the sole agent that brought about the dissociation of steam in this case. In the first place the dissociating influence of the highly heated surfaces of platinum on steam had to be taken into consideration, and, secondly, the chemi.al affinity which platinum had for oxygen, and still more for hydrogen. The same remarks applied to Meyer's experiment of passing steam or carbonic acid through heated platinum tubes, in which case he obtained only traces of dissociation, the temperature being much lower. Other experiments might be mentioned, but none led to a different conception of the question.

There is one other circumstance connected with dissociation, proved by experiment, which, however, required explanation. It was considered as a sure sign that dissociation was going on when a flame whose temperature was raised became longer; this it was said could only be accounted for by dissociation having commenced. He agreed with this conclusion, but the experiments by which it had heen proved had been made, like others referred to, in narrow tulues or passages in which the dissociating action of the heated surfaces must come into play. It was not alone the heat to which the gases were raised that in these cases caused dissociation and increased the length of the flame, but also the influence of the heated surfaces in contact with the combustible gases, more e pecially if these gases contained hydrocarbons. The extension of the flame was also partly due to the obstruction which the surfaces offered to the recombusti in of the dissociated gases through want of space. If the same flame were allowed free developmen in a spice unencu nbered by surfaces, as in the lecturer's radiation furnace, no such extension of its length would be observed ; but, on the contrary, it would get shorter with increase of temperature. This action could be best observed in the regenerative gas-burner exhibited, whose flame became shorter the greater the intensity of the temperature, and therefore of the light, produced. On the other hand, flame might be extended almost to any length if conducted through narrow passages; this might be seen in regenerative furnaces, which would send the flame to the top of the chimney if the reversing valves were so arranged that the flame, instead of passing through the furnace chamber, was made to burn directly down into the regenerators. No proper combustion could then take place in the brick checkerwork of the regenerative chambers, and the flame would consequently continue to extend until co led down below a red heat, being ultimately converted into dark smoke; thus in this case the extensive surfaces offered by regenerators would act both ways, by preventing combustion, and by assisting dissociation.

It would be understood that regenerative furnaces themselves offered special opportunities for making experiments, most questions, indeed, being best settled by the results obtained in actual work. If dissociation set in the consequences were seen in want of heat, reduced output, and in destruction of furnace and material. If the causes of dissociation were removed, a rise in temperature, increased output, longer furnace life, and saving of material ensued. Similar results might be obtained with other furnaces, but the beneficial action would not be so great as in the case of the regenerative furnace, because the intensity of heat obtainable in them was much lower.

After describing a new regenerative gas stove he had lately introduced, the lecturer referred to the better distribution of the radiated heat by its use; he found that a room warmed by means of a stove or open fire, such as described, was of a more unifurm temperature than when warmed by an ordinary fire or by a gas and coke fire, such as his brother was engaged in introducing into this country shortly before his death.

This, in his opinion, was mainly due to the fact that a source of radiant heat of low intensity but of Jarge surface, sending out its rays at various angles, heated an object in its vicinity very much more than was the case with a smaller source of radiant heat of greater intensity, whose rays struck the object from one direction only, notwithstanding that both sources radiated the same quantity of heat. This action was illustrated by means of two diagrams exhibited, which represented two rooms, the one heated by a small flame of high intensity, and the other by a large flame of low intensity, both radiating the same quantity of heat. In each room two objects, globes or spheres, were repre- 
sented, the one close to, and the other at a distance from the source of heat. The object in the one room near to the source having the large heating surface was almost enveloped in rays, while that in the second received rays only in one direction, the former therefore being much more heated than the latter. This difference did not occur when the two globes at a distance from the two sources of heat were compared. The law that the rays of heat diminished in the inverse ratio of the square of the distance was only correct as regards small but intense sources of heat, whilst the decrease of radiant heat took place in a much higher proportion in the case of large sources of heat of low intensity. This clearly proved that for the purpose of warming rooms by means of radiation, it was important that the beat should be concentrated in an intensely hot focus, as was the case in nature, our earth being warmed in this way by the radiant action of the sun.

\section{ON THE EFFECT OF HEAT IN CHANGING THE STRUCTURE OF CRYSTALS OF POTASSIUM CHLORATE}

$\mathrm{I} \mathrm{T}$ was observed some time ago by M. Mallard (Bulletin de la Société Minêralogique, 1882, p. 2r4) that certain crystals, such as boracite and potassium sulphate, have their crystallographic character profoundly modified by exposure to a high temperature, and that in the case of potassium sulphate a number of hemitrope plates are thus formed.

Now, potassium chlorate, while it does not belong to the same crystal-family as potassium sulphate, shows a still more inveterate tendency to produce twins (such as would assuredly drive a Malthus to despair). It was therefore an obvious inference that heat might produce a similar physical change in this substance, although I have not been able to find any account of the experiment having been tried. The decrepitation of crystals of potassium chlorate, when heated, has of course been noted; but the wreck of the crystal has been always rather inadequately explained as due to the vaporisation of included films of water.

A clear transparent crystal of potassium chlorate, from which the inevitable twin plate had been ground away so as to reduce it to a single crystal-film about $1 \mathrm{~mm}$. in thickness, was placed between pieces of mica and laid on a thick iron plate. About $3 \mathrm{~cm}$. from it was laid a small bit of potassium chlorate, and the heat of a Bunsen burner was applied below this latter, so as to obtain an indication when the temperature of the plate was approaching the fusing-point of the substance $\left(359^{\circ} \mathrm{C}\right.$., according to Prof. Carnelley). The crystal-plate was carefully watched during the heating, but no decrepitation took place, and no visible alteration was observed, up to the point at which the small sentinel crystal immediately over the burner began to fuse. The lamp was now withdrawn, and when the temperature had sunk a few degrees a remarkable change spread quickly and quietly over the crystal-plate, causing it to reflect light almost as brilliantly as if a film of silver had been deposited on it. No further alteration occurred during the cooling; and the plate, after being ground and polished on both sides, was mounted with Canada balsam between glass plates for examination. Many crystals have been similarly treated with precisely similar results; and the temperature at which the change takes place has been determined to lie between $245^{\circ}$ and $248^{\circ}$, by beating the plates upon a bath of melted tin in which a ther mometer was immersed. With single crystal-plates no decrepitation has ever been observed, while with the ordinary twinned plates it always occurs more or less violently, each fragment showing the brilliant reflective power above noticed. Doubtless the decrepitation is due to the wrenching asunder of the hemitrope plates, caused by their unequal expansion by heat in different directions.

The following brief account will show the nature of the changes which the crystal has undergone:-

(I) Examined in common white light, the ordinary crystals of potassium chlorate reflect no more light, either superficially or internally, than a plate of glass, in whatever position they are viewed.

The altered crystals, when similarly. examined, reflect little light at small angles of incidence, but at all angles greater than about $10^{\circ}$ they reflect light with a brilliancy which shows that the reflection must be almost total. This reflective power does not seem to be materially greater at high angles of incidence.
When the plate is turned round in its own plane, two positions are found, differing in azimuth by $180^{\circ}$, in which the crystal reflects no more light than an ordinary crystal under the same conditions. In these cases the plane of incidence coincides with the plane of crystallographic symmetry.

The reflected beam is slightly iridescent; and when the plate is held obliquely and examined with a magnifier, a striated faintly-coloured structure is observable, resembling that of watered silk or mother-of-pearl. The coloured bands always lie parallel to the plane of symmetry. When the reflected light is examined with a spectroscope, it is found to give a rather complicated spectrum containing numerous narrow absorptionbands. In some specimens these bands are fairly straight and regular, but in most cases they are rather wavy, and rary in thickness in different parts of their length, appearing somewhat like the interlacing twigs in a bundle of sticks. As the angle of incidence is increased, these bands move towards the more refrangible end of the spectrum, while others appear and join in the procession.

The spectrum of the transmitted light is, of course, strictly complementary to that of the reflected beam; and both of them strongly resemble the spectra given by some of the iridescent crystals described by Prof. Stokes (see NATURE, vol. xxxi. p. 565), and also by many sections of opal and mother-of-pearl, and by films of decomposed glass.

(2) When examined in a parallel beam of plane-polarised light, the ordinary crystals show little or no colour, unless held so that the light passes nearly in the direction of the optic axes, when the usual broad, rather faintly-coloured bands are seen. The altered crystals, on the contrary, give in all positions (except when the light passes through nearly normally, or when the plane of polarisation is either parallel or perpendicular to the plane of symmetry) a most complicated and brightly-coloured pattern, resembling that which is shown by many of the complicated macled crystals of amethystine quartz, which vary, like patterns on watered silk, with slight changes in the direction of incidence of the light

(3) When examined in a micro-polariscope, in plane-polarised, highly convergent white light, the ordinary crystals show the usual isochromatic lemniscates surrounding the optic axes, which latter are themselves just visible at the edge of the field. In the altered crystals nothing of the kind is visible, only patches of colour distributed rather irregularly over the field, somewhat like those of certain of Nörremberg's mica-selenite combinations.

(4) When homogeneous (sodium) light was substituted for white light in the micro-polariscope (an expedient which is of great use in simplifying and giving definiteness to the phenomena shown by crystals), the remarkable nature of the structural change which heat had caused was much more clearly apparent. The ordinary crystals simply showed the usual multitude of curved isochromatic bands symmetrically arranged round the optic axes and filling the whole field. The altered crystals showed nothing of the kind; but a set of hyperbolas appeared-the form of the isochromatic curves of extremely high order which are given by biaxial crystals when the directions of the optic axes make a very large angle with the normal to the surface of the plate (see Verdet, Euvres, vol. vi. pp. I72-175). These hyperbolas are not rectangular, thus proving that the optic axes do not lie in the plane of the plate (as in the case of cleavage plates of selenite); but they so nearly do this that I could not, even by immersing the plate in oil, satisfictorily determine their precise position. The bands are rather irregular and shifty, as is usual in composite macles; in some parts of a crystal they may appear as the central portions of a lemniscate-system.

(5) It seemed desirable to examine the effect of heat upon the crystal during its progress, so as to determine whether the change of structure takes place at the period of the formation of the reffective layer. For this purpose a polished plate of potassium chlorate was clasped in a copper holder (like that used for plates of selenite in Mitscherlich's well-known experiment), so that it could be placed in the field of the polariscope and examined while its temperature was gradually raised by the application of a lamp-flame to the outer extremity of the holder.

The ordinary set of isochromatic curves lasted nearly unchanged for some time as the temperature rose, but at a certain point they faded away like a dissolving view; and then out of the confusion there emerged the set of hyperbolas above mentioned, which grew in definiteness and regularity, but did not 